Check for updates

Cite this: Chem. Sci., 2019, 10, 2212

๑ All publication charges for this article have been paid for by the Royal Society of Chemistry

Received 26th September 2018 Accepted 18th December 2018

DOI: $10.1039 / \mathrm{c} 8 \mathrm{sc} 04277 \mathrm{~b}$

rsc.li/chemical-science

\section{Alder-ene reactions driven by high steric strain and bond angle distortion to form benzocyclobutenes $\uparrow$}

\begin{abstract}
Saswata Gupta, ${ }^{a}$ Yongjia Lin, ${ }^{b}$ Yuanzhi Xia, (D) *b Donald J. Wink ${ }^{a}$ and Daesung Lee (D) *a
A unique aryne-based Alder-ene reaction to form benzocyclobutene is described. In this process, the thermodynamic barrier to form a four-membered ring is compensated by the relief of the strain energy of an aryne intermediate. On the other hand, the driving force to overcome the high kinetic barrier is provided by the gearing effect of the bulky substituent at the ortho-position of the ene-donor alkene. To maximize the steric strain by the ortho-substituent, a structural element for internal hydrogen bonding is installed, which plays a crucial role for both the hexadehydro Diels-Alder and the Alder-ene reactions. DFT calculations show that the bulky hydrogen bonding element lowers the activation barrier for the Alder-ene reaction by destabilizing the intermediate, which is due to the severe bond angle distortion. The preferred formation of cis-isomers can also be explained by the extent of bond angle distortion.
\end{abstract}

A variety of chemical transformations have been developed relying on the high reactivity of arynes, which is generally manifested through a strained alkyne, 1,2-diradical, or 1,2zwitterionic character depending on the reacting counterpart. ${ }^{1}$ In the presence of silver salt as a catalyst, ${ }^{2}$ yet another mode of reactivity was revealed, which is best formulated as a 1,2dicarbene/carbenoid. Among many reactions involving arynes, the Alder-ene reaction has been shown to be one of the most efficient processes wherein arynes behave as a powerful eneacceptor. ${ }^{3}$ Our interest in aryne-mediated Alder-ene reactions prompted us to explore both intramolecular and intermolecular Alder-ene reactions of arynes ${ }^{4}$ generated via the hexadehydro Diels-Alder reaction. ${ }^{5}$

In our endeavor to further expand the scope of aryne-based Alder-ene reactions, we were intrigued by the possibility of an intramolecular Alder-ene reaction to form a four-membered ring, which is expected to be extremely difficult, and thus has not been reported to the best of our knowledge (Scheme 1). The paucity of four-membered ring formation via a thermal Alderene reaction is due to not only the ring-strain of the incipient ring but also the geometrical constraints for the cyclic transition state. In the case of an aryne as an ene-acceptor, however, the relief of its high strain energy may provide a sufficient driving force for the reaction to proceed to form benzocyclobutenes. ${ }^{6}$ This reagent-free access to compounds containing a benzocyclobutene substructure would be meritorious since

${ }^{a}$ Department of Chemistry, University of Illinois at Chicago, 845 West Taylor Street, Chicago, Illinois 60607, USA. E-mail: dsunglee@uic.edu

${ }^{b}$ College of Chemistry and Materials Engineering, Wenzhou University, Wenzhou, Zhejiang Province 325035, P. R. China. E-mail: xyz@wzu.edu.cn

$\dagger$ Electronic supplementary information (ESI) available: Detailed experimental procedure and ${ }^{1} \mathrm{H}$ and ${ }^{13} \mathrm{C}$ spectra. CCDC 1843923 . For ESI and crystallographic data in CIF or other electronic format see DOI: $10.1039 / \mathrm{c} 8 \mathrm{sc} 04277 \mathrm{~b}$ they are known as important building blocks for natural products, ${ }^{7}$ pharmaceutical ingredients ${ }^{8}$ and advanced materials. ${ }^{9}$

The calculated Gibbs free energy for the Alder-ene reaction suggests that the product formation has a sufficient thermodynamic driving force ( $c a .50-63 \mathrm{kcal} \mathrm{mol}^{-1}$ ). To overcome the expected kinetic barrier, installation of a structural element (I) is expected to be crucial, whereby the steric bulk of the substituent will gear the ene-donor alkene via angle distortion to attain an appropriate transition state. ${ }^{10}$ In the actual substrate (II) the ortho-isopropanol moiety is expected to serve as an effective gearing element through internal hydrogen bonding. In this hydrogen-bonded conformation, the steric pressure exerted by the gem-dimethyl group against the enedonor moiety would promote its interaction with the aryne moiety more effectively, which would facilitate the formation of benzocyclobutene (III).

Having these concerns in mind, we designed propiolatebased triyne substrates $\mathbf{1 a}-\mathbf{h}$ and ynamide-based tetrayne $\mathbf{1 i}$ and triyne $\mathbf{1} \mathbf{j}$ (Table 1). These substrates contain a substituent that will impose a variable degree of steric interactions with the prenyl group at the transition state of the Alder-ene reaction. A prenyl group was chosen as the ene-donor based on its most favorable capacity for Alder-ene reactions. ${ }^{11}$ When triyne 1a

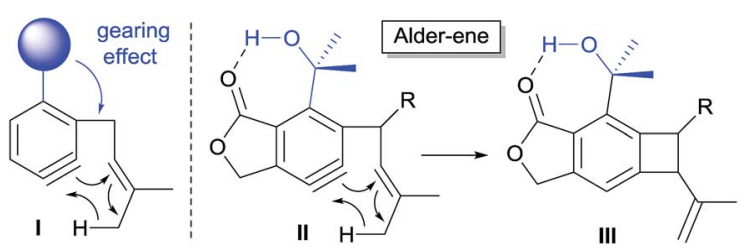

Scheme 1 Aryne-mediated Alder-ene driven by hydrogen bonding and steric pressure. 
Table 1 Effect of steric bulk and hydrogen bonding on the aryne Alder-ene reaction

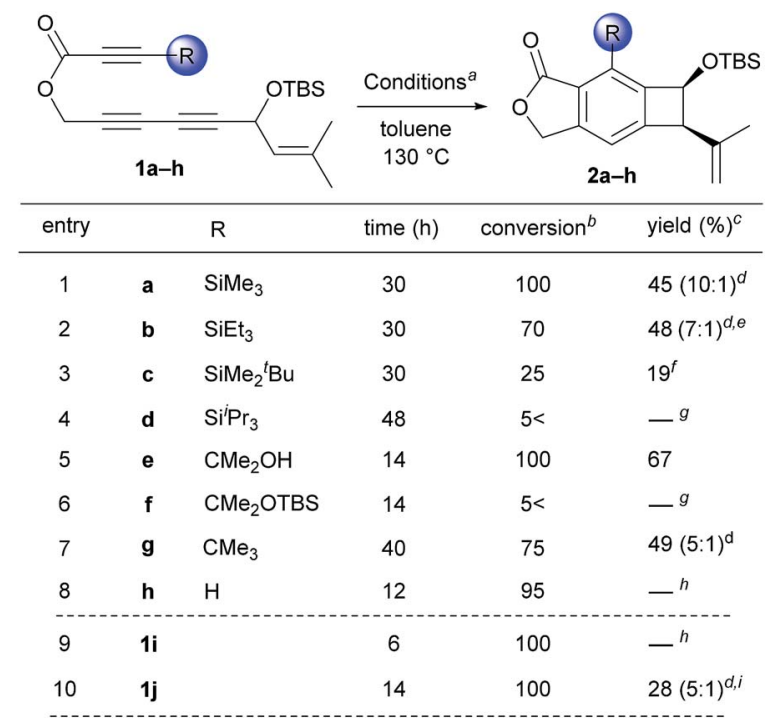
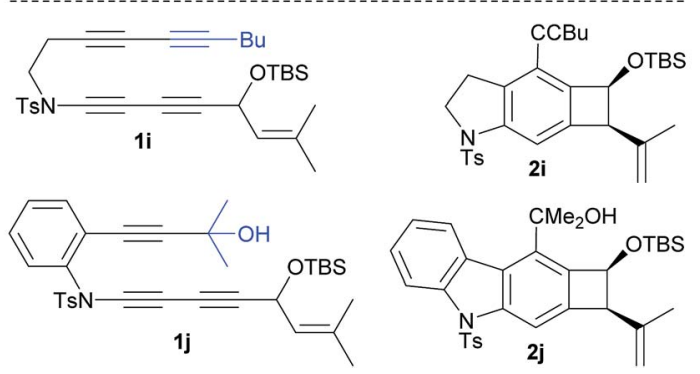

${ }^{a}$ 20-25 mg scale of $1 .{ }^{b}$ Determined by ${ }^{1} \mathrm{H}$ NMR of crude mixtures. ${ }^{c}$ Isolated yield. ${ }^{d}$ Diastereomeric ratios. ${ }^{e} 52 \%$ yield with $75 \%$ conversion at $150{ }^{\circ} \mathrm{C}, 40$ h. ${ }^{f}$ Determined by ${ }^{1} \mathrm{H}$ NMR with an internal standard. ${ }^{g}$ Starting material intact at $130{ }^{\circ} \mathrm{C}$ but decomposed at $170{ }^{\circ} \mathrm{C}$. ${ }^{h}$ No product observed with decomposition of the starting materials. ${ }^{i}$ Heating at $90{ }^{\circ} \mathrm{C}$.

bearing a trimethylsilyl group ( $\mathrm{SiMe}_{3}, \mathrm{TMS}$ ) was heated at $130^{\circ} \mathrm{C}$ (toluene), complete conversion was reached after $30 \mathrm{~h}$ and the isolated product was identified as the Alder-ene product $2 \mathbf{a}$ in $45 \%$ yield (entry 1). Unexpectedly, the predominant diastereomer of $2 \mathrm{a}(10: 1 \mathrm{dr})$ was confirmed to have a cis-relationship between the silyloxy and isopropenyl groups. Under the same conditions, triyne $\mathbf{1} \mathbf{b}$ containing a triethylsilyl group ( $\left.\mathrm{SiEt}_{3}, \mathrm{TES}\right)$ showed similar reactivity, affording product $2 \mathrm{~b}$ in $48 \%$ yield (entry 2). The reaction of 1c containing a tert-butyldimethylsilyl group ( $\mathrm{SiMe}_{2}{ }^{t} \mathrm{Bu}, \mathrm{TBS}$ ) was much slower, resulting in $25 \%$ conversion after $30 \mathrm{~h}$ to produce $2 \mathrm{c}$ in $19 \%$ yield (entry 3 ). Triyne 1d containing a triisipropylsilyl group ( $\mathrm{Si}^{\mathrm{i}} \mathrm{Pr}_{3}$, TIPS) remained intact even after $48 \mathrm{~h}$ (entry 4 ), which seems to be the consequence of extreme steric bulk of the TIPS group that prohibits the formation of an aryne intermediate. Gratifyingly, triyne $\mathbf{1 e}$ containing an isopropanol moiety $\left(\mathrm{CMe}_{2} \mathrm{OH}\right)$ afforded Alder-ene product $2 \mathrm{e}$ as a single diastereomer (for nOe data showing the cis-relationship see s32 and s33 of the ESI $\dagger$ ) in $65 \%$ yield with full conversion within $14 \mathrm{~h}$ (entry 5 ). The ${ }^{1} \mathrm{H}$ NMR of product $2 \mathrm{e}$ shows a characteristic sharp singlet at 6.2 ppm suggesting a hydrogen-bonded hydroxyl group. To compare the role of hydrogen bonding, similar substrates without a free hydroxyl group such as $\mathbf{1 f}$ and $\mathbf{1 g}$ were tested. While the TBS ether $\mathbf{1 f}$ showed little conversion $(<5 \%)$ (entry 7$)$, ${ }^{t}$ butyl-containing substrate $1 \mathrm{~g}$ afforded $2 \mathrm{~g}$ ( $5: 1 \mathrm{dr}$ ) in $45 \%$ yield at $75 \%$ conversion after $40 \mathrm{~h}$ (entry 6 and 7 ). Triyne $\mathbf{1 h}$ containing an unsubstituted propiolate moiety did not provide an Alder-ene product although full conversion was achieved within $12 \mathrm{~h}$ (entry 8). As expected this is the consequence of relatively facile formation of an aryne intermediate but the Alder-ene reaction did not occur due to the lack of the necessary gearing effect. By the same token, the failure of a tetrayne $1 \mathbf{i}$ in producing $2 \mathbf{i}$ is the consequence of a small steric bulk of the 1-hexynyl substituent (entry 9). The important role of the hydrogen bonding was further demonstrated by a carbonyl-free triyne $\mathbf{1 j}$ containing a $\mathrm{CMe}_{2} \mathrm{OH}$ substituent, which provided $2 \mathrm{j}$ in only $28 \%$ yield although full conversion was achieved within $14 \mathrm{~h}$ (entry 10).

Having identified the crucial elements for the 4-memberedring forming Alder-ene reaction of aryne species, we next examined the structural requirement of the ene-donor moiety (Table 2). Triyne $\mathbf{1 k}$, identical to $\mathbf{1 e}$ but devoid of a silyloxy group, afforded $\mathbf{2 k}$ in $72 \%$ yield (entry 1 ). In contrast, a free hydroxyl-containing substrate $\mathbf{1 l}$ afforded product $\mathbf{2 l}$ in significantly lower yield (30\%) (entry 2). We surmise that an alternative hydrogen bonding by the secondary hydroxyl group may perturb the hydrogen bonding of the $3^{\circ}$ hydroxyl group at the stage of the ene reaction. This hypothesis is supported by a new broad singlet at $5.6 \mathrm{ppm}$, which is significantly different from the characteristic signal in other products including 2 e. This clearly suggests the beneficial effect of the hydrogen bonding between $3^{\circ}$ hydroxyl groups and the lactone carbonyl for the Alder-ene reaction. A structural limitation was recognized from the failure of triyne $\mathbf{1} \mathbf{m}$ in generating Alder-ene product $\mathbf{2 m}$ (entry $3)$. We assume that this failure is caused by the severe steric interaction between the aryne moiety and the incipient quaternary carbon center at the transition state of the ene reaction. Unexpectedly, triyne 1 n containing a trans-disubstituted ene-donor did not generate $2 \mathbf{n}$ instead the starting material was decomposed (entry 4). Triyne 10 containing a geraniol moiety afforded 20 in $67 \%$ yield $(E / Z, 2.5: 1)$ (entry 5 ). On the other hand, triyne $1 p$ containing a nerol moiety afforded a single isomer $2 \mathbf{p}$ in $62 \%$ yield, where only the methyl group reacted to become a methylidene moiety (entry 6). This is consistent with the previous observations that only the distal allylic $\mathrm{C}-\mathrm{H}$ bonds on the trans-position of ene-donor alkenes can participate in the intramolecular Alder-ene reaction. ${ }^{3 a}$ Despite the possibility of forming an 8-membered ring, the exclusive formation of 4 -membered ene product $\mathbf{2 p}$ from a nerol-derived substrate 1p suggests that a kinetic preference to form a 4-membered ring may override the thermodynamic preference to form an 8-membered ring. Triyne 1q tethered with a 3-methylcyclohexen-1-ol moiety afforded cyclohexane-fused benzocyclobutene $2 \mathrm{q}$ in $56 \%$ yield (entry 7 ). The reaction of triyne 1r provided 2r where the gem-dimethyl bridge should control the cis-ring junction stereochemistry, which was confirmed by nOe experiments and X-ray diffraction analysis ${ }^{\mathbf{1 2}}$ (entry 8). As expected, $2 \mathbf{r}^{\prime}$ containing a triethylsilyl group was 
Table 2 Effect of the substituents on the ene-donor
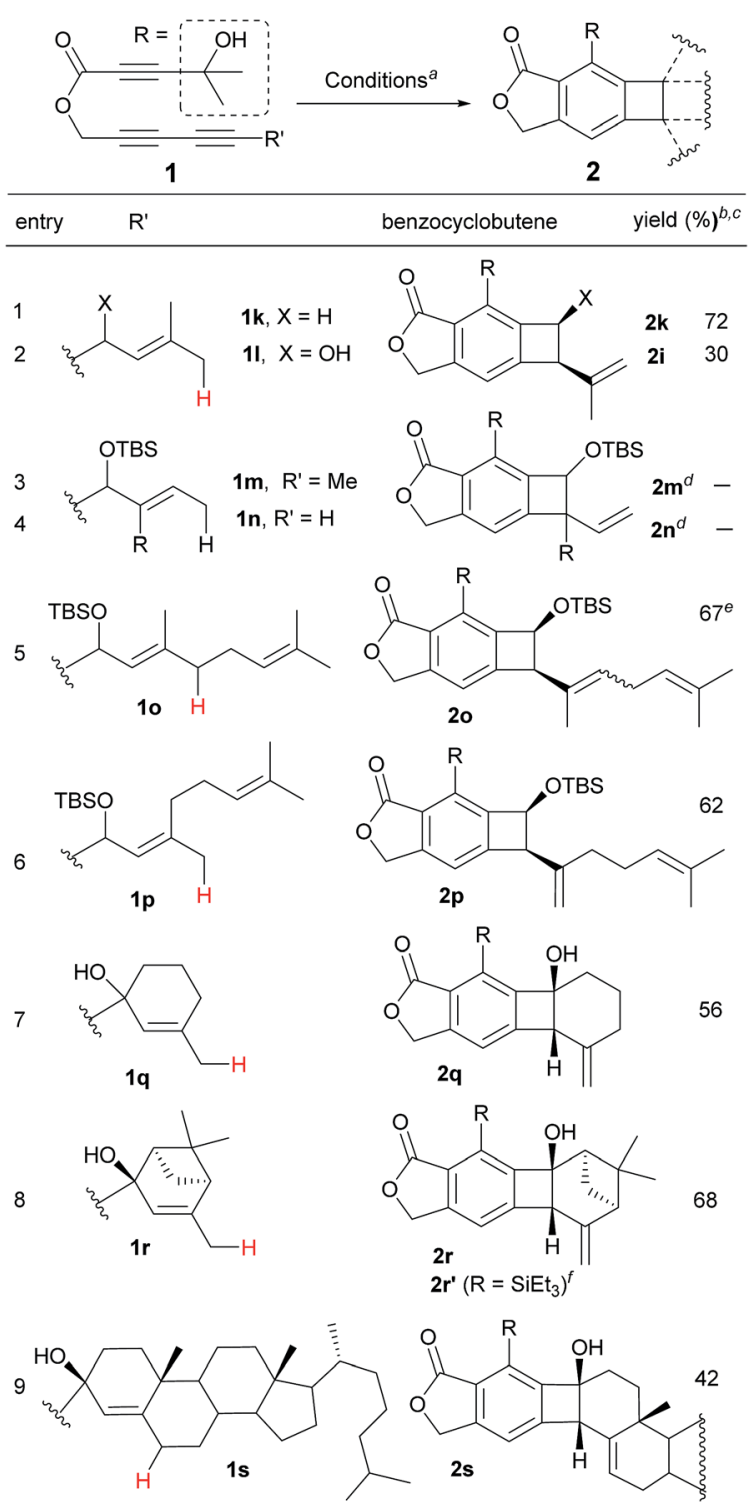

10<smiles>CCOC(C=C1CCCCCCC1)CC</smiles>

11

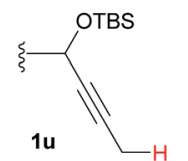

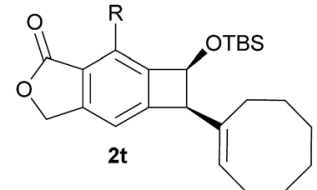

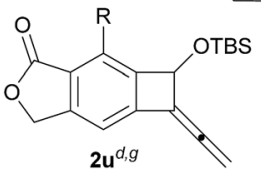

${ }^{a}$ Conditions: toluene, $130{ }^{\circ} \mathrm{C}, 14 \mathrm{~h} .{ }^{b}$ Isolated yield. ${ }^{c}$ cis-Diastereomer only. ${ }^{d}$ Decomposition or polymerization of the aryne intermediates. ${ }^{e} E / Z$-mixture $(2.5: 1) .{ }^{f}$ With $\mathrm{R}=\mathrm{SiEt}_{3}, 2 \mathrm{r}^{\prime}$ was obtained in $46 \%$ yield at $150{ }^{\circ} \mathrm{C}$ at $40 \mathrm{~h} .{ }^{g}$ Intermolecular Alder-ene reaction with $\beta$-pinene (5 equiv.) of $1 \mathbf{u}$ provided $2 \mathbf{u}^{\prime}$ (see ref. 13).

obtained in $46 \%$ yield at higher temperature with a longer reaction time $\left(150{ }^{\circ} \mathrm{C}, 40 \mathrm{~h}\right)$ compared to $2 \mathrm{r}$ which was obtained in $68 \%$ at $130{ }^{\circ} \mathrm{C}$ within $14 \mathrm{~h}$. A cholesterol-derived triyne $1 \mathrm{~s}$ afforded $2 \mathrm{~s}$ in $42 \%$ yield (entry 9 ). The relatively low yield of $2 \mathrm{~s}$ is assumed to be the consequence of a conformationally restricted ene-donor methylene unit within the decaline system. On the other hand, triyne 1t tethered with a cyclooctylidene moiety afforded benzocyclobutene $2 \mathrm{t}$ in $69 \%$ yield, where the enedonor methylene conformation should be more flexible to achieve an appropriate transition state for the ene reaction (entry 10). Under the same conditions, triyne $\mathbf{1} \mathbf{u}$ bearing an alkyne ene-donor was consumed but the Alder-ene product $2 \mathbf{u}$ was not obtained (entry 11). In the presence of $\beta$-pinene $(5$ equiv.) however, $\mathbf{1 u}$ afforded product $\mathbf{2} \mathbf{u}^{\prime}$ in $76 \%$ yield via an intermolecular reaction. ${ }^{13}$ This suggests that the putative aryne intermediate was formed properly from 1r but the Alder-ene reaction between the aryne and the tethered propyne moiety failed. This is presumably because of the difficulty in accessing the required transition state with the alkyne moiety of linear geometry.

Table 3 Reactivity of triynes of different tethers ${ }^{a}$
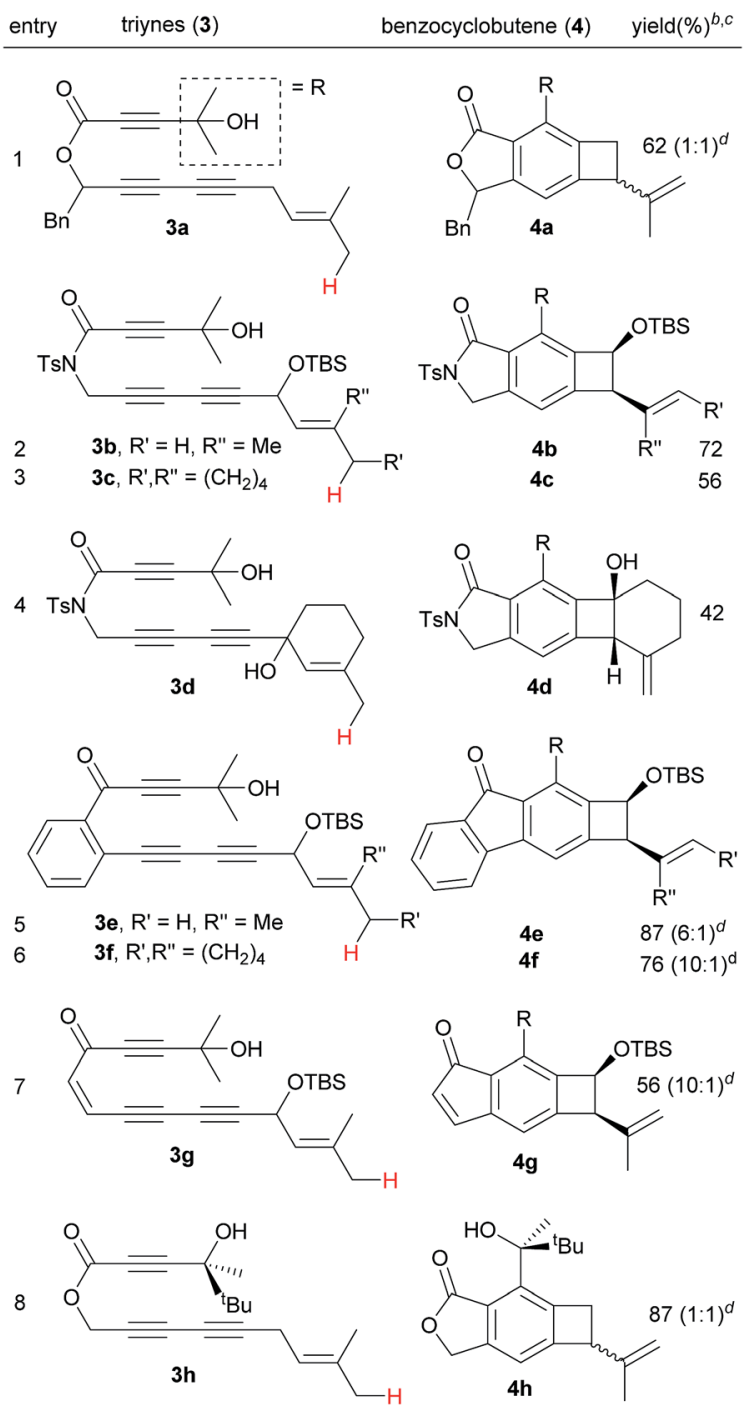

${ }^{a}$ Conditions: toluene, $90{ }^{\circ} \mathrm{C}, 14 \mathrm{~h} .{ }^{b}$ Isolated yield. ${ }^{c}$ Diastereomeric ratio as determined by ${ }^{1} \mathrm{H}$ NMR of crude. ${ }^{d}$ At $130^{\circ} \mathrm{C}, 14 \mathrm{~h}$. 

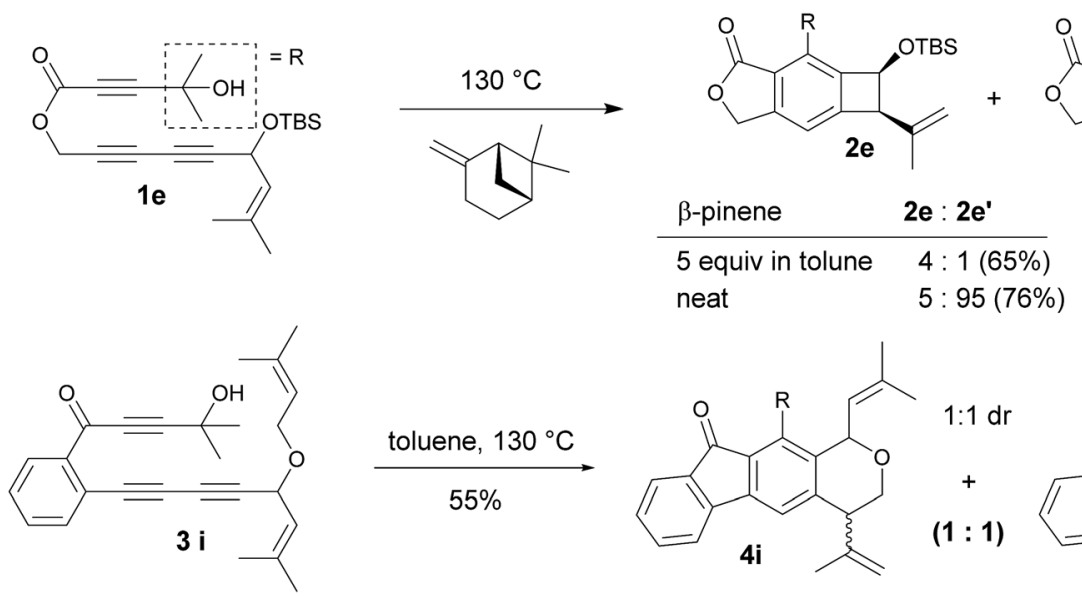

\begin{tabular}{ll}
$\beta$-pinene & $\mathbf{2 e}: \mathbf{2 e}$ \\
\hline 5 equiv in tolune & $4: 1(65 \%)$ \\
neat & $5: 95(76 \%)$
\end{tabular}<smiles>[R6]OC(C=C(C)C)c1cc(CC2=CCC3CC2C3(C)C)c([2H])c2c1C(=O)NC2</smiles>
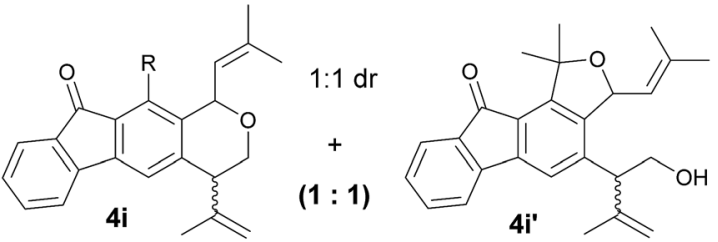

Scheme 2 Inter vs. intramolecular Alder-ene reaction.

Next, we investigated the effect of the tether of triynes on the efficiency of the Alder-ene reaction (Table 3). Triyne 3a with a benzylic substituent afforded $4 a$ as a $1: 1$ mixture of diastereomers in $62 \%$ yield (entry 1 ). Imide-tethered triynes $3 \mathbf{b}$ and $\mathbf{3 c}$ containing a gem-dimethyl or a cyclohexylidene moiety provided 4b and $\mathbf{4 c}$ in 72 and 56\% yield (entries 2 and 3). Triyne 3d with a 3-methyl cyclohexen-1-ol moiety afforded $\mathbf{4 d}$ in relatively low yield (42\%). In the same vein, arene-tethered triynes $3 \mathbf{e}$ and $\mathbf{3 f}$ afforded 4 e and $\mathbf{4 f}$ in 87 and $76 \%$ yield (entries 5 and 6). Triyne $3 \mathrm{~g}$ with an enone tether generate indenone $\mathbf{4 g}$ in $56 \%$ yield (entry 7). A racemic chiral alcohol $\mathbf{3 h}$ with sterically differentiated methyl and tert-butyl groups did not lead to the relative stereochemical induction, thus affording $\mathbf{4 h}$ as a $1: 1$ diastereomer in $87 \%$ yield (entry 8 ).

The competition for intramolecular Alder-ene reactions to form a strained benzocyclobutene versus an intermolecular reaction was examined with triyne 1e (Scheme 2). With 5 equivalents of $\beta$-pinene, a $4: 1$ mixture of $2 \mathrm{e}$ and $2 \mathrm{e}^{\prime}$ was obtained but the ratio changed to $5: 95$ in neat $\beta$-pinene. An internal competition with triyne $3 \mathbf{i}$ provided 6 -membered ring
(SMD)MO6/6-311++G(d,p)//B3LYP/6-31G(d)
(Energy in kcal/mol)

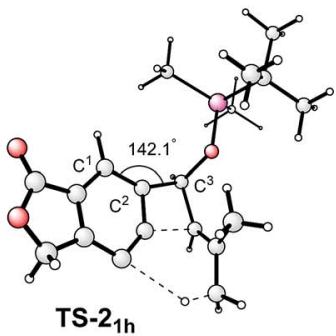<smiles>C=C(C)C1c2cc3c(cc2C1O[13CH2])C(=O)OC3</smiles>

$2 h^{\prime}$ (trans)

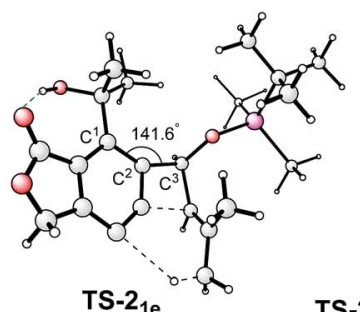

TS-2 $1 \mathrm{~h}^{\prime}$
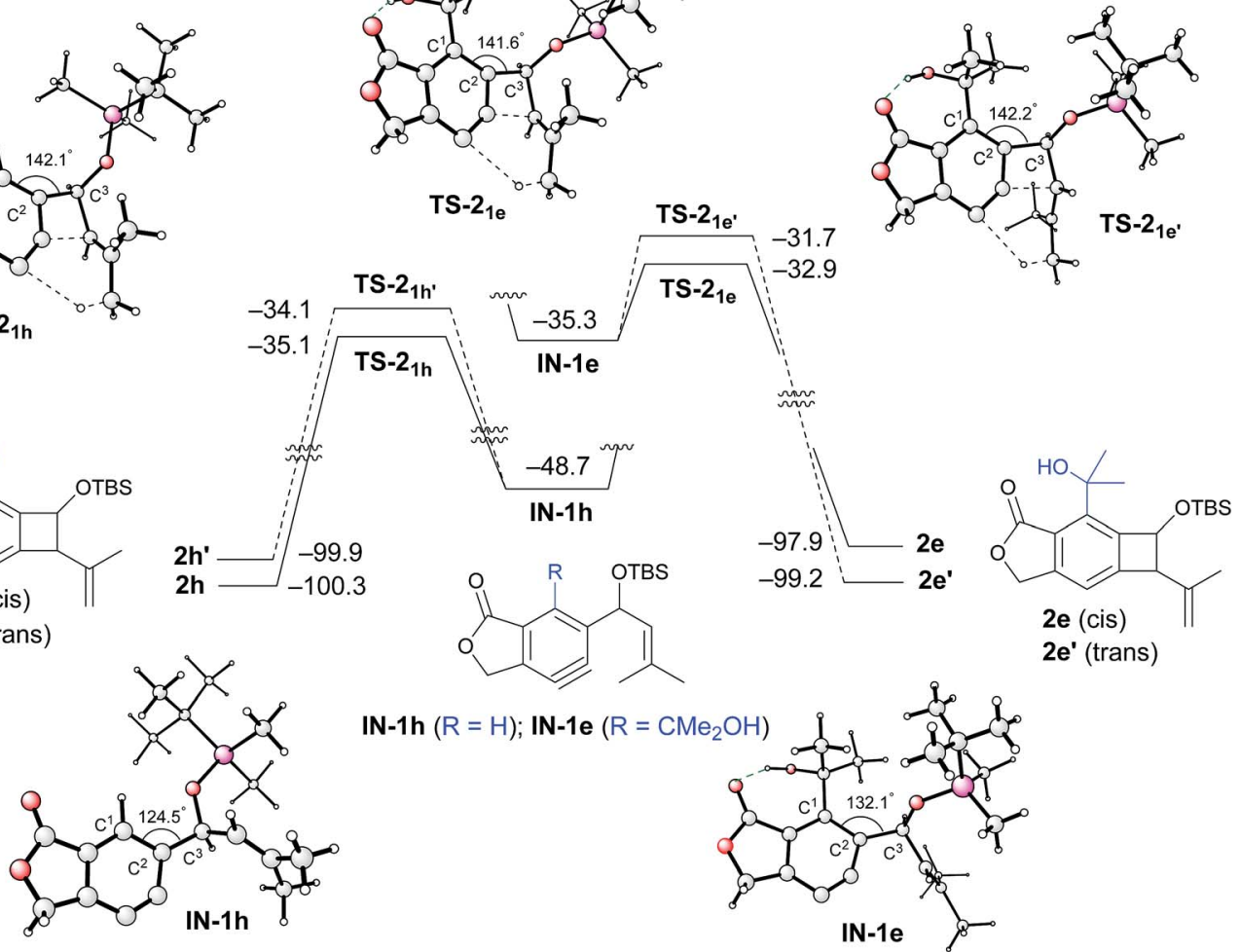

$2 e^{\prime}$ (trans)

Scheme 3 DFT-based analysis of the energy profiles of Alder-ene reactions and the origin of cis-selectivity. 

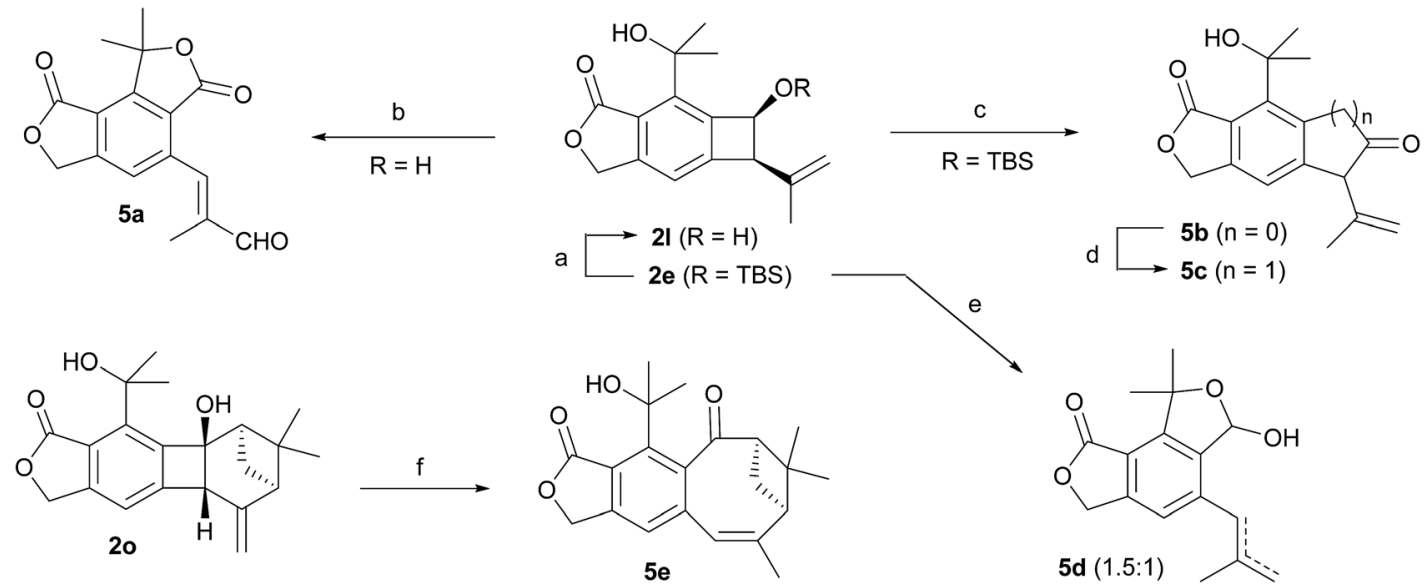

Scheme 4 Reactions of benzocyclobutene derivatives. Conditions: (a) 10 -camphorsulfonic acid, $\mathrm{MeOH}-\mathrm{CH}_{2} \mathrm{Cl}_{2}(1: 1), \mathrm{rt}, 80 \%$. (b) $\mathrm{MnO}{ }_{2}$ (excess), $\mathrm{CH}_{2} \mathrm{Cl}_{2}, \mathrm{rt}, 72 \%$. (c) Dess-Martin periodinane, $\mathrm{CH}_{2} \mathrm{Cl}_{2}, \mathrm{rt}, 82 \%$. (d) $\mathrm{TMSCHN}_{2}, \mathrm{BF}_{3} \cdot \mathrm{Et}_{2} \mathrm{O}, \mathrm{CH}_{2} \mathrm{Cl}_{2},-20{ }^{\circ} \mathrm{C}, 55 \%$. (e) TBAF, THF, rt, $86 \%$. (f) $\mathrm{NaH}, \mathrm{THF}, 50{ }^{\circ} \mathrm{C}, 81 \%$

product $4 \mathbf{i}$ along with its derivative $4 \mathbf{i}^{\prime} \cdot{ }^{14}$ This indicates that the formation of a 6-membered ring is much more favorable than that of a 4-membered ring via the ene reaction.

To gain insight into the role of the hydrogen bonding and the unexpected cis-stereoselectivity, the Alder-ene reactions of aryne intermediates IN-1e and IN-1h were compared by DFT calculations (Scheme 3).$^{15}$ The more facile Alder-ene reaction of IN-1e is due to a smaller angle distortion by $c a .10^{\circ}$ for reaching the transition states $\mathbf{T S}-\mathbf{2}_{\mathbf{1 e}}$ and $\mathbf{T S}-\mathbf{2}_{\mathbf{1 e}}$, compared to $c a .18^{\circ}$ for $\mathbf{I N}-\mathbf{1 h}$ to reach $\mathbf{T S}-\mathbf{2}_{\mathbf{1 h}}$. This difference then translates to an activation energy difference of more than $11 \mathrm{kcal} \mathrm{mol}^{-1}$ between these two systems. Although trans-isomer $2 \mathbf{e}^{\prime}$ is more stable than cis-isomer $2 \mathrm{e}$ by $1.3 \mathrm{kcal} \mathrm{mol}^{-1}$, the energy of TS- $\mathbf{2}_{\mathbf{1 e}}$ is lower than that of TS- $\mathbf{2}_{1 \mathrm{e}^{\prime}}$ by $1.2 \mathrm{kcal} \mathrm{mol}^{-1}$, which can be attributed to the slightly lower angle distortion in TS-2 $\mathbf{2}_{\mathbf{1 e}}$, leading to the formation of cis-diastereomer $2 \mathbf{e} .^{16}$

Finally, the benzocyclobutenes generated by Alder-ene reactions could be converted to various other molecular structures via ring expansion or cleavage of the 4-membered ring (Scheme 4). Oxidation of benzocyclobutenol $2 \mathbf{l}$ with $\mathrm{MnO}_{2}$ resulted in ring opening followed by two independent subsequent allylic oxidations, generating enal $\mathbf{5 a}$ in good yield. However, efficient oxidation of $\mathbf{2 l}$ to the corresponding ketone $\mathbf{5 b}$ could be achieved with Dess-Martin periodinane. One-carbon insertion into $\mathbf{5 b}$ afforded $\mathbf{5 c}{ }^{17}$ Treating silyl ether $2 \mathbf{e}$ with TBAF resulted in the ring-opened product $\mathbf{5 d}$ as a mixture $(1.5: 1)$ of a terminal and an internal alkene. Also, direct ring expansion of the cyclobutanol moiety of 20 cleanly afforded cyclooctenone $5 \mathbf{e}$ under basic conditions.

In summary, we have explored the Alder-ene reaction of arynes to form benzocyclobutenes, which was affected by installing a bulky substituent next to the ene-donor alkene moiety. It was found that internal hydrogen bonding is crucial not only to facilitate the hexadehydro Diels-Alder reaction to form an aryne intermediate but also to promote its Alder-ene reaction. DFT calculations revealed that the major role of the bulky hydrogen bonding element is to lower the activation barrier by destabilizing the intermediate, which is due to severe bond angle distortion. The transition state leading to the cisisomer is more stable than the trans-isomer by $1.2 \mathrm{kcal} \mathrm{mol}^{-1}$, which is the consequence of slightly lower bond angle distortion than the transition state leading to the trans-isomer. This reagent-free method to form substituted benzocyclobutene scaffolds would be useful for natural product synthesis and transition metal-catalyzed transformations. ${ }^{18}$

\section{Conflicts of interest}

There are no conflicts to declare.

\section{Acknowledgements}

We are grateful to NSF (CHE-1764141, D. L.) and NSFC (21873074 and 21572163, Y. X.) for financial support. The Mass Spectrometry Laboratory at UIUC is acknowledged.

\section{Notes and references}

1 General reviews on aryne chemistry: (a) P. M. Tadross and B. M. Stoltz, Chem. Rev., 2012, 112, 3550-3577; (b) C. M. Gampe and E. M. Carreira, Angew. Chem., Int. Ed., 2012, 51, 3766-3778; (c) S. S. Bhojgude, A. Bhunia and A. T. Biju, Acc. Chem. Res., 2016, 49, 1658-1670; (d) T. Roy and A. T. Biju, Chem. Commun., 2018, 54, 2580-2594.

2 Review: R. Karmakar and D. Lee, Chem. Soc. Rev., 2016, 45, 4459-4470, and references therein.

3 (a) T. T. Jayanth, M. Jeganmohan, M.-J. Cheng, S.-Y. Chu and C.-H. Cheng, J. Am. Chem. Soc., 2006, 128, 2232-2233; (b) D. A. Candito, J. Panteleev and M. Lautens, J. Am. Chem. Soc., 2011, 133, 14200-14203; (c) D. A. Candito, D. Dobrovolsky and M. Lautens, J. Am. Chem. Soc., 2012, 134, 15572-15580; (d) Z. Chen, J. Liang, J. Yin, G.-A. Yu and S. H. Liu, Tetrahedron Lett., 2013, 54, 5785-5787; (e) D. Niu and T. R. Hoye, Nat. Chem., 2014, 6, 34-40; $(f)$ P. Pérez and L. R. Domingo, Eur. J. Org. Chem., 2015, 2015, 2826-2834; (g) J. Zhang, D. Niu, V. A. Brinker and T. R. Hoye, Org. Lett., 
2016, 18, 5596-5599; (h) P. Trinchera, W. Sun, J. E. Smith, D. Palomas, R. Crespo-Otero and C. R. Jones, Org. Lett., 2017, 19, 4644-4647.

4 (a) R. Karmakar, P. Mamidipalli, S. Y. Yun and D. Lee, Org. Lett., 2013, 15, 1938-1941; (b) S. Gupta, P. Xie, Y. Xia and D. Lee, Org. Lett., 2017, 19, 5162-5165.

5 (a) A. Z. Bradley and R. P. Johnson, J. Am. Chem. Soc., 1997, 119, 9917-9918; (b) K. Miyawaki, R. Suzuki, T. Kawano and I. Ueda, Tetrahedron Lett., 1997, 38, 3943-3946; (c) T. R. Hoye, B. Baire, D. Niu, P. H. Willoughby and B. P. Woods, Nature, 2012, 490, 208-212; (d) Y. Hu, Y. Hu, Q. Hu, J. Ma, S. Lv, B. Liu and S. Wang, Chem.-Eur. J., 2017, 23, 4065-4072. For reviews: (e) C. Holden and M. F. Greaney, Angew. Chem., Int. Ed., 2014, 53, 5746-5749; (f) O. J. Diamond and T. B. Marder, Org. Chem. Front., 2017, 4, 891-910.

6 Other methods for benzocyclobutene synthesis: (a) K. P. C. Vollhardt, Angew. Chem., Int. Ed., 1984, 23, 539556; (b) M. Iwao, J. Org. Chem., 1990, 55, 3622-3627; (c) I. S. Aidhen and J. R. Ahuja, Tetrahedron Lett., 1992, 33, 5431-5432; (d) F. Toda, K. Tanaka, I. Sano and T. Isozaki, Angew. Chem., Int. Ed., 1994, 33, 1757-1758; (e) T. Matsumoto, H. Yamaguchi, T. Hamura, M. Tanabe, Y. Kuriyama and K. Suzuki, Tetrahedron Lett., 2000, 41, 8383-8387; (f) M. Chaumontet, R. Piccardi, N. Audic, J. Hitce, J.-L. Peglion, E. Clot and O. Baudoin, J. Am. Chem. Soc., 2008, 130, 15157-15166; $(g)$ P. Álvarez-Bercedo, A. Flores-Gaspar, A. Correa and R. Martin, J. Am. Chem. Soc., 2010, 132, 466-467; (h) V. R. Yedulla, P. Pradhan, L. Yang and M. K. Lakshman, Eur. J. Org. Chem., 2015, 2015, 750-764; (i) T. Yano, T. Kawasaki, T. Yuhki, N. Ishida and M. Murakami, Org. Lett., 2018, 20, 1224-1227.

7 (a) W. Oppolzer and K. Keller, J. Am. Chem. Soc., 1971, 93, 3836-3837; (b) F. A. J. Kerdesky, R. J. Ardecky, M. V. Lakshmikantham and M. P. Cava, J. Am. Chem. Soc., 1981, 103, 1992-1996; (c) M. Petit, G. Chouraqui, P. Phansavath, C. Aubert and M. Malacria, Org. Lett., 2002, 4, 1027-1029; for reviews: (d) G. Mehta and S. Kotha, Tetrahedron, 2001, 57, 625-659; (e) A. K. Sadana, R. K. Saini and W. E. Billups, Chem. Rev., 2003, 103, 1539-1602.

8 (a) S. Graf-Christophe, C. Kuehm-Caubere, P. Renard, B. Pfeiffer, A. Pierŕe, S. Léonce and P. Caubére, Bioorg. Med. Chem. Lett., 2000, 10, 2589-2591; (b) A. Tsotinis, P. A. Afroudakis, P. J. Garratt, A. Bocianowska-Zbrog and D. Sugden, ChemMedChem, 2014, 9, 2238-2243; (c) C. Zhang, F. Li, Y. Yu, A. Huang, P. He, M. Lei, J. Wang,
Z. Huang, Z. Liu, J. Liu and Y. Wei, J. Med. Chem., 2017, 60, 3618-3625.

9 (a) G. Sakellariou, H. Ji, J. W. Mays, N. Hadjichristidis and D. Baskaran, Chem. Mater., 2007, 19, 6370-6372; (b) Y. Cheng, J. Yang, Y. Jin, D. Deng and F. Xiao, Macromolecules, 2012, 45, 4085-4091.

10 (a) S. K. Ghosh and T. K. Sarkar, Tetrahedron Lett., 1986, 27, 525-528; (b) K. Narasaka, Y. Hayashi and S. Shimada, Chem. Lett., 1988, 17, 1609-1612; a general review on gem-dimethyl effect: (c) M. E. Jung and G. Piizzi, Chem. Rev., 2005, 105, 1735-1766.

11 K. Mikami and M. Shimizu, Chem. Rev., 1992, 92, 10211050.

12 X-Ray crystallographic data of 20 (CCDC 1843923) $\dagger$.

13 In presence of 5.0 equiv. of $\beta$-pinene $1 \mathbf{u}$ formed $2 \mathbf{u}^{\prime}$ by an intermolecular Alder-ene reaction in 55\% yield as a $1: 1$ mixture of diastereomers. This result clearly shows that the formation of aryne intermediate from this substrate is not a problem.
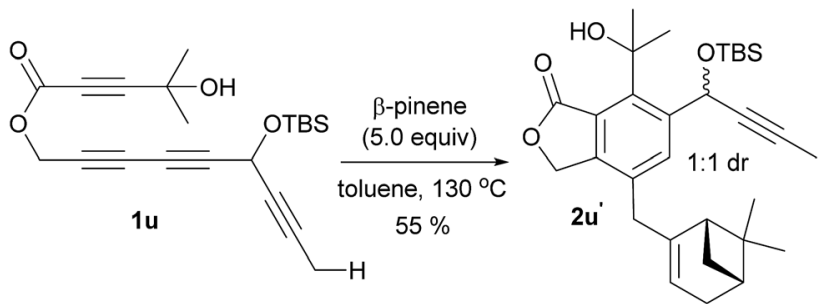

14 The secondary product $\mathbf{4} \mathbf{i}^{\prime}$ is assumed to be generated from 4i via a thermal benzylic alkoxy exchange reaction.

15 All solvation energies; are relative to that of the starting material. The full detail can be found in the ESI. $\dagger$

16 The reaction profile of substrate $\mathbf{1 g}$ lacking the hydrogen bonding element was also calculated (see ESI $\dagger$ for details).

17 J.-H. Youn, J. Lee and J. K. Cha, Org. Lett., 2001, 3, 2935-2938. 18 (a) T. Xu and G. Dong, Angew. Chem., Int. Ed., 2012, 51, 75677571; (b) N. Ishida, S. Sawano, Y. Masuda and M. Murakami, J. Am. Chem. Soc., 2012, 134, 17502-17504; (c) N. Ishida, N. Ishikawa, S. Sawano, Y. Masuda and M. Murakami, Chem. Commun., 2015, 51, 1882-1885; (d) F. JuliáHernández, A. Ziadi, A. Nishimura and R. Martin, Angew. Chem., Int. Ed., 2015, 54, 9537-9541; (e) P.-H. Chen, J. Sieber, C. H. Senanayake and G. Dong, Chem. Sci., 2015, 6, 5440-5445. 